\title{
LUT
}

University

\section{Reactivity characterization of municipal solid waste and biomass}

Nikku Markku, Deb Anjan, Sermyagina Ekaterina, Puro Liisa

This is a Final draft version of a publication

published by Elsevier

in Fuel

DOI: $10.1016 /$ j.fuel.2019.115690

Copyright of the original publication: () 2019 Elsevier Ltd.

Please cite the publication as follows:

Nikku, M., Deb, A., Sermyagina, E., Puro, L. 2019. Reactivity characterization of municipal solid waste and biomass, Fuel, vol. 254. DOI: https://doi.org/10.1016/j.fuel.2019.115690.

This is a parallel published version of an original publication.

This version can differ from the original published article. 

Lappeenranta, Finland

b) Technical Services, School of Engineering Science, Lappeenranta University of Technology, P.O. Box 20, FI-53851 Lappeenranta, Finland

*Corresponding author: Tel.: +358 40501 5201, E-mail address: mnikku@lut.fi (M. Nikku).

Keywords: municipal solid waste, biomass, sewage sludge, reactivity characterization, TGA.

9

10

11

12

13

14

15

16

17

18

19

20

21

\section{Abstract}

The composition, heating value, and reactivity of different municipal and industrial solid waste materials were studied and compared with biomass and coal samples. Reactivity characterization was performed in a vertical tube reactor by dropping a pelletized sample on a porous grid and monitoring the conversion of the sample by Fourier-transform infrared spetroscopy. Samples were tested in ambient oxygen atmosphere at three temperatures typical to incinerator applications, and in reduced oxygen atmospheres, that better represents conditions near the fuel feeding points in incinerators. Thermogravimetrical analysis was used to analyze selected samples and reactivity information was compared with the vertical tube reactor results. This research provides information on the material composition and reactivity for utilization of munical solid waste and sewage sludge in incineration applications. Comparison of two characterization methods illustrates that the characterization method has a significant effect on the reaction rate results, with the implication that the reaction characterization method should be selected to represent the actual conditions of the application. 


\section{Nomenclature}

24

A pre-exponential factor

$\left[\mathrm{s}^{-1}\right]$

$25 \quad C$

amount of carbon

[mol]

$26 E$

activation energy

$\left[\mathrm{J} \mathrm{mol}^{-1}\right]$

$27 d$

diameter

[m]

28

density

$\left[\mathrm{kg} \mathrm{m}^{-3}\right]$

$29 \quad k$

reaction rate

$\left[\mathrm{s}^{-1}\right]$

$30 \quad m$

mass

$[\mathrm{kg}]$

$31 \quad T$

temperature

$[\mathrm{K}]$

$32 x$

conversion degree

$[-]$

33 Subscripts and superscripts

34

35

36

specie

37 tot

at time $0 \mathrm{~s}$

$38 \infty$

at the end of reactions

\section{$39 \quad$ Abbreviations}

40 DSC differential scanning calorimetry

41 FTIR Fourier-transform infrared spectroscopy mass spectrometry

42 HHV higher heating value

43 MS mass spectrometry

44 MSW municipal solid waste

45 TGA thermogravimetric analysis 
The increasing volumes of waste materials being generated and growing concerns about the environment are leading to calls for more research related to unsolved issues in the processing and utilization of waste streams. Extensive knowledge of the nature and characteristics of each waste fraction are essential for selection of the most suitable treatment techniques and effective capture of any problematic or hazardous compounds in the waste. Incineration is a widely adopted method for treatment of combustible fractions of municipal solid waste (MSW) that cannot be reused or recycled, as incineration offers the possibility to recover the material as energy, thus reducing combustion of fossile fuels for power generation [1]. Incineration also reduces the amount of waste material by up to $80 \%$ by volume or $70 \%$ by mass [2]. MSW includes organic and inorganic fractions from households and offices, such as cellulosic materials (various types of paper, cardboard, waste wood, etc.), food waste, plastic, rubber, glass, metals, and various other materials. MSW is a very heterogeneous material and, furthermore, its properties and composition depend on the source [3], season [4,5], and origins of the waste. Additionally, MSW properties vary for different countries as well as for different regions within a country $[6,7]$. While certain industrial waste fractions are typically subjected to material and energy recovery on site, some fraction are sent to municipal waste treatment facilities for processing with MSW.

Incineration is also suitable for another problematic and common waste stream - sewage sludge. Sewage sludge is produced at municipal waste water treatment plants and contains mainly organic material with traces of various harmfull substances such as heavy metals, pathogens, micro-plastics, and hormones [8]. The importance of incineration of sewage sludge is increasing because alternative methods such as anaerobic digestion, aerobic composting and landfilling are facing serious limitations due to increasingly stringent legislation on acceptable post-treatment applications for sludge-derived products $[1,9]$. Sewage sludge is considered as a challenging material for mono-incineration, as it represents a potential source of toxic pollutants, and due to its high moisture (up to $80 \mathrm{wt} . \%$ after mechanical dewatering) and ash content [10]. Co-incineration of sewage sludge with MSW or other fuels offers an attractive way to overcome these 
challenges and to be enable energy recovery [1,10-12]. Appropriate flue gas treatment methods can reduce harmful emissions to the environment [13].

Research in to combustion properties of materials is required for estimation of their suitability for incineration, selection of incineration strategy, design of incinerator as well as modeling of the combustion process [12,14-16]. Relevant chemical properties of the fuel are chemical and elemental composition, chemical reactivity, heating value and possible reaction products; while the physical properties, such as material density, particle size and shape distributions and porosity, have a limited effect on apparent reactivity but they have a significant effect on how the fuel behaves mechanically and hydrodynamically.

Thermogravimetric analysis (TGA) is widely used in reactivity studies [17-20]. In TGA, the weight of a solid sample is constantly monitored and the gas atmosphere around the sample is heated at a constant rate until a desired temperature level is reached. TGA can be coupled with differential scanning calorimetry (DSC), mass spectrometry (MS) or Fourier-transform infrared spectroscopy (FTIR) to obtain additional data on the heat released/absorbed by the sample or the gas species released from the sample. For representative results, the TGA conditions, for example heating rates, must match those found inside incinerators, which is not always the case. Additional limitation in comparison with real applications is that the samples for TGA typically have to be reduced to fine powder in order to meet the sample size requirements of the device. The gas flow conditions and mode of species transport in TGA might also differ from incineration applications. Another method used for reactivity characterization is testing in a drop tube reactor, where fuel particles are dropped into a heated reactor and quenched after they have fallen a certain distance. After quenching, the particles can be analysed for changes in physical properties and chemical composition [21-24]. While optical methods such as high speed video capture and pyrometers can be used to monitor movement and temperature of the sample, limited information can be obtained about the reactions while the sample is inside the reactor. Examples of other characterization methods can be found in the literature, Murphy et al. [25] utilized an entrainment flow reactor, where instead of dropping, the particles are transported upwards by gas flow. Kijo-Kleczkowska et al. [26] studied reactivity 
of pelletized samples suspended in an updraft reactor. Fang et al. [27] utilized a small fluidized bed to study reactivity of coal char. Adamczyk et al. [28] presented a method where the fuel particles are dropped into a horizontal "windtunnel" and changes in particle trajectories are analyzed to determine the reaction rate of the particles. Pilot testing has also been used in reactivity characterization to offer better correspondence with the specific application [29].

Combustion and co-combustion of different wastes and their blends have been studied actively, typically with TGA, for example, cardboard [30], lignocellulosic materials found in MSW [31], sewage sludge [26,32], plastics $[33,34]$ and pulp and paper mill sludge $[32,35,36]$. Gunasee et al. [37] investigated the thermal behavior of nine waste fractions and co-combustion of lignocellulosic and plastic-based mixture with results indicated positive synergies for co-combustion.

Although TGA is widely adopted to investigate the combustion behavior of different materials, including the waste streams, the applicability of its results to larger scale applications such as MSW incinerators is questionable. The reactivity parameters obtained even for the same materials may differ significantly depending on the characterization method, heating rate, flow conditions, material particle size and other factors. Alternative characterization methods, such as drop tube reactors, provide the reaction conditions that are closer to industrial applications [38].

In this work, several industrial and municipal solid waste fractions, sewage sludge and woody biomass, peat and coal samples are analyzed to determine their combustion properties, namely, moisture, volatile, fixed carbon and ash content, heating value and apparent reactivity at different temperatures and oxygen concentrations. The reactivity characterization was performed by dropping pelletized samples into a vertical quartz tube reactor with a sintered grid in the middle which retains the sample after the initial fall. This reactor design allows the complete combustion profile of volatiles and char to be captured with Fourier-transform infrared spectroscopy which was used to monitor the conversion process. Publications of a similar characterization method were not found in a literature survey, which supports the novelty of the presented approach. One aim of this research is to compare how different waste fractions differ in their 
combustion characteristics from more commonly utilized fuels, such as biomass or coal. Additionally, the results of the chosen characterization method are compared with the results of thermogravimetric analysis. The information obtained can be directly utilized in design of incinerator units and for modeling of waste material combustion.

\section{Experimental methods}

\subsection{Materials}

Municipal solid waste samples were collected from a landfill site in Southern Karelia, Finland. On-site the waste fractions were sorted into energy waste, which could be combusted for energy production, and demolition wood, which had been ground to wood chips. Different fractions of common household waste, such as paper, cardboard, plastic, cloth and liquid carton were sampled by hand from the wastepiles. Industrial waste samples were obtained from a pulp and paper plant operating in the same region, namely wood bark, residue from a saw mill and sludge from the plant's water treatment plant. Biomass fuel samples of forest residue and peat were obtained from a local power plant. Mechanically dewatered sewage sludge was obtained from the waste water treatment in city of Lappeenranta, Finland. Additionally, a sample of Polish bituminous coal was tested for comparison.

The samples were first dried in a laboratory oven for 24 hours to determine the moisture content. Next, the samples were shredded until they passed through a sieve in the shredder with an opening size of $1 \mathrm{~mm}$ afterwhich the material was mixed to increase homogeneity. The samples were then utilized in determination of the volatiles, ash and fixed carbon contents, and pressed into pellets, which were combusted in a bomb calorimeter to determine the heating value. Proximate analysis was performed for all material samples following SFS-EN standards. Additionally, a few of the sample materials were tested with NETZSCH STA 449C thermogravimeter for comparison. For the TGA, a couple of milligrams of each sample were placed inside a ceramic sample holder and heated at a rate of $20 \mathrm{~K} / \mathrm{min}$ until $900^{\circ} \mathrm{C}$, in standard air atmosphere. 


\subsection{Reactivity analysis}

The main reactivity analysis of was performed with a benchscale material reactivity analysis device, later referred as the benchscale device, where compressed sample pellets with a mass of $0.1 \mathrm{~g}$ and a diameter of $4 \mathrm{~mm}$ were combusted and the data from the combustion reactions were measured. The benchscale device, presented in Figure 1, consists of a quartz glass tube, with a length of $780 \mathrm{~mm}$ and diameter of 45 $\mathrm{mm}$, placed inside a tube furnace, which is capable of maximum temperature of $1100{ }^{\circ} \mathrm{C}$. A sintered quartz glass grate in the middle of the glass tube allows gases to pass through, while holding the solid material. The porous grate also makes the flow passing through it more uniform compared to a typical laminar flow profile inside a tube. The temperature and the gas atmosphere inside the glass tube can be controlled by heater control and mass flow controllers (MFC) for each gas species. The mass flow controllers also measure the flow rate of the bottled gases and compressed air from the network. After the reactor, the composition of the gaseous products leaving the reactor is analyzed online with Fourier-transform infrared spectroscopy (FTIR), afterwhich the gases are led to the stack. Additionally, two thermocouple probes are used to measure the temperature below and above the grate to maintain steady temperature level inside the tube. The sample pellets were fed individually into the reactor by dropping them from the feeding port at the top of the reactor to the grate where they complete their devolatilization and combustion of volatiles and char. A negligible amount of ash remained on the grate after the pellet combustion, due to low ash content of most samples as well as ash elutriation out of the reactor by the feed gas.

Characterization tests were performed in standard air atmosphere at temperatures of 700,800 and $900{ }^{\circ} \mathrm{C}$, and at a temperature of $800{ }^{\circ} \mathrm{C}$ with oxygen concentration reduced to $10 \%$ and $5 \%$ of volume using bottled $\mathrm{O}_{2}$ and $\mathrm{N}_{2}$ supply. The gas flow rate in all tests was kept constant at $0.05 \mathrm{In} / \mathrm{s}$, which corresponds to superficial gas velocities of 0.112 to $0.124 \mathrm{~m} / \mathrm{s}$. The corresponding Reynolds numbers range from 4.5 to 5 and 40.5 to 45.4 based on the pellet and the tube diameter, respectively. The Reynolds numbers show that the flow conditions and heat and mass transfer rates were relatively similar for each temperature. The feeding times were significantly shorter than the overall reaction times and the FTIR sampling rate. Each 
171 in changing temperature and oxygen atmospheres. Each material sample was tested with at least 5 pellets.

172 Pellet breakage during feeding or devolatilization led to deviating measurement results, and this data was 173 excluded from the analysis.

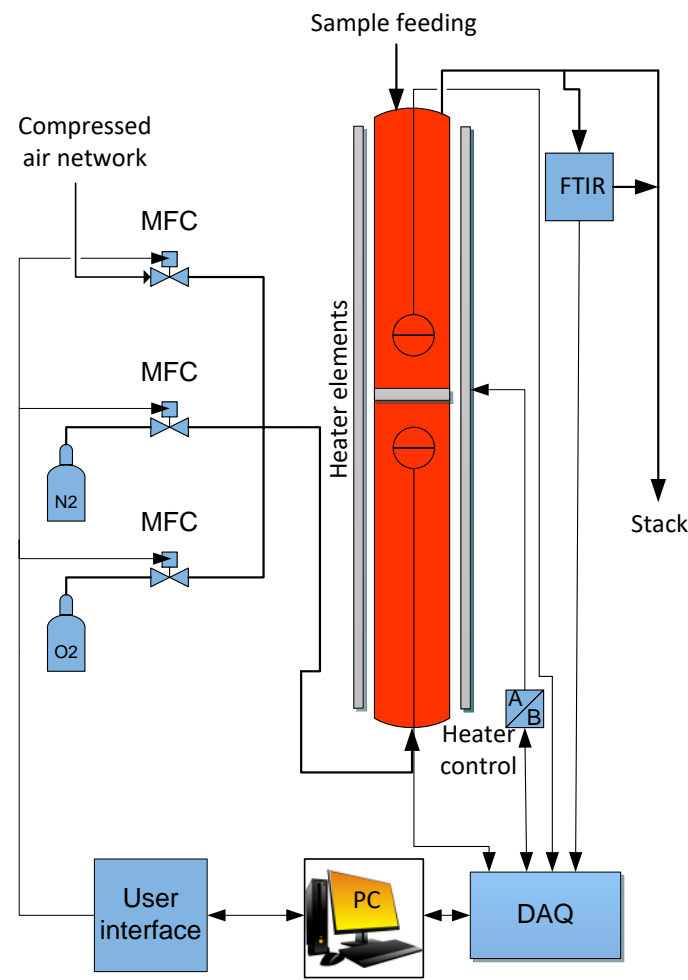

175 Figure 1. Schematics of the benchscale material reactivity analysis device.

Table 1. Characterization test matrix.

\begin{tabular}{lcccccc}
\hline \multicolumn{1}{c}{ Sample } & $\begin{array}{c}700{ }^{\circ} \mathrm{C}, \\
21 \%-\mathrm{O}_{2}\end{array}$ & $\begin{array}{c}800{ }^{\circ} \mathrm{C}, \\
21 \%-\mathrm{O}_{2}\end{array}$ & $\begin{array}{c}900{ }^{\circ} \mathrm{C}, \\
21 \%-\mathrm{O}_{2}\end{array}$ & $\begin{array}{c}800{ }^{\circ} \mathrm{C}, \\
10 \%-\mathrm{O}_{2}\end{array}$ & $\begin{array}{c}80{ }^{\circ} \mathrm{C}, \\
5 \%-\mathrm{O}_{2}\end{array}$ & $\begin{array}{c}\mathrm{TGA} \\
20 \mathrm{~K} / \mathrm{min}\end{array}$ \\
\hline Paper & $\mathrm{X}$ & $\mathrm{X}$ & $\mathrm{X}$ & & & \\
Cartboard & $\mathrm{X}$ & $\mathrm{X}$ & $\mathrm{X}$ & & & \\
Liquid cartons & $\mathrm{X}$ & $\mathrm{X}$ & $\mathrm{X}$ & & & \\
Plastics & $\mathrm{X}$ & $\mathrm{X}$ & $\mathrm{X}$ & $\mathrm{X}$ & $\mathrm{X}$ & $\mathrm{X}$ \\
Sewage sludge & $\mathrm{X}$ & $\mathrm{X}$ & $\mathrm{X}$ & $\mathrm{X}$ & $\mathrm{X}$ & $\mathrm{X}$ \\
Waste wood & $\mathrm{X}$ & $\mathrm{X}$ & $\mathrm{X}$ & & & $\mathrm{X}$ \\
Bark, paper & & $\mathrm{X}$ & & & & \\
Bark, pulp & & $\mathrm{X}$ & & & & \\
Saw mill residue & & $\mathrm{X}$ & & & & \\
Forest residue & $\mathrm{X}$ & $\mathrm{X}$ & $\mathrm{X}$ & $\mathrm{X}$ & $\mathrm{X}$ & $\mathrm{X}$ \\
Peat & $\mathrm{X}$ & $\mathrm{X}$ & $\mathrm{X}$ & $\mathrm{X}$ & $\mathrm{X}$ & $\mathrm{X}$ \\
Industrial sludge & $\mathrm{X}$ & $\mathrm{X}$ & $\mathrm{X}$ & $\mathrm{X}$ & $\mathrm{X}$ & $\mathrm{X}$ \\
Coal & $\mathrm{X}$ & $\mathrm{X}$ & $\mathrm{X}$ & $\mathrm{X}$ & $\mathrm{X}$ & $\mathrm{X}$ \\
\hline
\end{tabular}


177 The apparent reaction rate $k$ is commonly expressed with the Arrhenius equation (Eq. 1). To find the

178 reactivity parameters, logarithm of Equation 1 yields Equation 2, which gives the activation energy $E$ and

179 pre-exponential factor $A$ in the Arrhenius equation as the slope and $y$-intercept determinable from the $\ln k$,

$1801 / T$-plot. As the rate constant $k$ is temperature dependent, the samples have to be tested in several

181 temperatures in order to obtain $A$ and $E$.

$182 \frac{d X}{d t}=k=A \exp \left(-\frac{E}{R T}\right)$

$\ln k=\ln A-E / R T$

The conversion of a sample is commonly is determined with mass basis in TGA and drop tube analysis with Equation 3.

$$
X=\frac{m_{0}-m_{i}}{m_{0}-m_{\infty}}
$$

where $X$ is the conversion in time $t$. In this work, a similar analysis to Fang et al. [27] is used, where the conversion is determined from the measured output gas composition instead of sample mass, as the gas composition is measured online unlike of the sample mass. All the carbon containing species $n$ are added together for each time step $i$ and compared to the total released carbon, presented in Equation 4. The main gaseous species containing most of the carbon are $\mathrm{CO}_{2}$ and $\mathrm{CO}$, with trace amounts of $\mathrm{CH}_{4}$ and other uncombusted volatiles in a few cases.

$$
X=\frac{\sum_{n} \sum_{i} C_{n, i}}{C_{t o t}}
$$

Compared to a open-ended drop tube, longer residence times are achievable with the benchscale device as the sample is retained inside the reactor. Additionally, larger particles can be utilized. On the other hand, the sample will always react fully as it is not possible to remove the sample. Compared to TGA, where the sample is placed inside a ceramic cup which partially prevents the sample from being in direct contact with 
the gas flow and where thermal decomposition and diffusion of oxidizer and products have a significant influence on the conversion process, in the benchscale device the direct gas flow on the sample through the porous grate reduces the share of diffusion in the species transport to and from the surface of the sample. These differences are likely to affect the reaction rates obtained from each characterization method, with the expectation of lower reaction rates due to increased diffusion resistance and lower heating rate in TGA.

\section{Results and discussion}

\subsection{Proximate analysis and heating value measurements}

Table 2 presents data obtained from the proximate analysis and the bomb calorimetric analysis. It is noteworthy that, on a dry basis, all waste fractions contain a high share of volatile matter, while fixed carbon (i.e. char) and ash shares vary, for example, paper, plastic and sewage sludge contained higher shares of ash than fixed carbon. In the biomass samples, the moisture and volatiles shares were high, while the share of ash is very low. It can be seen that the higher heating values of the different waste fractions are of the same order as those of widely utilized biomass fuels. The higher heating value does not include the effect of fuel moisture, which lowers the amount of heat that can be extracted from the combustion process. The lowest heating value was found for paper, which can be explained by the high share of ash. 

samples.

\begin{tabular}{lccccc}
\hline Sample & Moisture, a.r. & Volatiles, d.b. & Fixed carbon, d.b. & Ash, d.b. & HHV, d.b. \\
\hline Cardboard & 19.5 & 78.65 & 15.17 & 6.18 & 17.91 \\
Juicebox & 55.3 & 82.84 & 9.97 & 7.18 & 23.95 \\
Paper & 48.6 & 56.35 & 7.63 & 36.02 & 12.17 \\
Plastic & 53.2 & 92.43 & 0.21 & 7.36 & 40.72 \\
Sewage sludge & 66.1 & 82.20 & 6.60 & 11.20 & 19.56 \\
Textile & 44.2 & 76.31 & 17.18 & 6.51 & 23.67 \\
Waste wood & 39.4 & 79.04 & 19.67 & 1.28 & 20.26 \\
Bark, paper line & 9.1 & 80.52 & 17.33 & 2.15 & 20.18 \\
Bark, pulp line & 10.5 & 75.19 & 22.07 & 2.74 & 21.06 \\
Industrial sludge & 18.9 & 81.03 & 17.07 & 1.90 & 19.89 \\
Saw mill residue & 28.0 & 74.00 & 23.98 & 2.02 & 20.72 \\
Coal & 18.6 & 24.28 & 59.47 & 16.26 & 29.53 \\
Forest residue & 8.2 & 76.45 & 19.20 & 4.34 & 20.67 \\
Peat & 75.9 & 63.55 & 28.61 & 7.84 & 21.21 \\
\hline
\end{tabular}

\subsection{TGA}

Figure 2 presents the mass and differential mass measured with TGA for the samples. The summarized characteristic temperatures, reaction rates and share of residue for the materials tested with TGA are presented in Table 3. Coal curves are clearly visible, differing from other materials as coal reacts at higher temperatures. With coal, a significantly higher temperature of $343^{\circ} \mathrm{C}$ was required for devolatilization to start, while plastic and organic samples started reacting already at temperatures around 190 to $240{ }^{\circ} \mathrm{C}$. There are two distinct local minimums in the DTG curves of all materials, except coal which had a continuous mass loss curve with a single minimum in the the DTG curve, thus there is no clear indication of end of volatile combustion and beginning of char combustion. Similar TGA profiles for coal can be found in the literature $[39,40]$. It could be, that thermal decomposition of coal char continues simultaneous with the oxidation of solid char, which is supported by shares of volatiles and char of proximate analysis data. Thus, the maximum conversion rates are the same for devolatilization and char conversion as by the used

229 definitions they occur around the only local minimum in the DTG curve.

230 Plastic had the largest average apparent reactivity and high mass derivative during the devolatilization.

231 High devolatilization rates were also measured with waste wood, forest residue and sludge, while lower 
232

233 significantly lower compared to the devolatilization rates and also quite similar between different samples,

234 with the exception of plastic, which has almost negligible amount of char (see Table 1) and this is the likely

235 explanation for this result. The average reaction rates are similar between plastic, sludge, waste wood and

243 of each material.

244 Table 3. TGA measured conversion data.

\begin{tabular}{|c|c|c|c|c|c|c|c|c|c|c|c|}
\hline Sample & $\begin{array}{c}\mathrm{T} 1 \\
{\left[{ }^{\circ} \mathrm{C}\right]}\end{array}$ & $\begin{array}{c}\mathrm{T} 2 \\
{\left[{ }^{\circ} \mathrm{C}\right]}\end{array}$ & $\begin{array}{c}\mathrm{T} 3 \\
{\left[{ }^{\circ} \mathrm{C}\right]}\end{array}$ & $\begin{array}{c}\mathrm{T} 4 \\
{\left[{ }^{\circ} \mathrm{C}\right]}\end{array}$ & $\begin{array}{c}\mathrm{T} 5 \\
{\left[{ }^{\circ} \mathrm{C}\right]}\end{array}$ & $\begin{array}{c}\mathrm{dm} / \mathrm{dt} \\
(\mathrm{T} 1-\mathrm{T} 3) \\
{[\% / \mathrm{min}]}\end{array}$ & $\begin{array}{c}\mathrm{dm} / \mathrm{dt} \\
(\mathrm{T} 2) \\
{[\% / \mathrm{min}]}\end{array}$ & $\begin{array}{c}\mathrm{dm} / \mathrm{dt} \\
(\mathrm{T} 3-\mathrm{T} 5) \\
{[\% / \mathrm{min}]}\end{array}$ & $\begin{array}{c}\mathrm{dm} / \mathrm{dt} \\
(\mathrm{T} 4) \\
{[\% / \mathrm{min}]}\end{array}$ & $\begin{array}{c}\mathrm{dm} / \mathrm{dt} \\
\text { mean } \\
{[\% / \mathrm{min}]}\end{array}$ & $\begin{array}{c}\text { Residue } \\
\text { [\%] }\end{array}$ \\
\hline $\begin{array}{l}\text { Sewage } \\
\text { sludge }\end{array}$ & 226 & 316 & 375 & 473 & 584 & -5.94 & -7.90 & -2.85 & -4.99 & -4.06 & 18 \\
\hline Peat & 190 & 310 & 353 & 412 & 590 & -5.07 & -8.90 & -4.00 & -6.85 & -4.39 & 8.7 \\
\hline Coal* & 343 & 561 & 561 & 561 & 850 & -4.18 & -5.14 & -3.61 & -5.14 & -3.20 & 16.4 \\
\hline Plastic & 245 & 460 & 488 & 500 & 590 & -7.49 & -16.37 & -0.97 & -3.24 & -5.51 & 4.4 \\
\hline Sludge & 240 & 336 & 376 & 466 & 560 & -8.34 & -18.04 & -3.29 & -4.59 & -5.30 & 9.7 \\
\hline $\begin{array}{l}\text { Waste } \\
\text { wood }\end{array}$ & 226 & 342 & 386 & 499 & 580 & -7.44 & -16.96 & -3.48 & -4.88 & -5.21 & 4.8 \\
\hline $\begin{array}{l}\text { Forest } \\
\text { residue }\end{array}$ & 221 & 334 & 371 & 473 & 555 & -7.53 & -18.81 & -3.52 & -5.54 & -5.20 & 10.6 \\
\hline
\end{tabular}

245 T1: start of devolatilization, T2: temperature of maximum devolatilization rate, T3: start of char combustion, T4: forest residue, with sewage sludge and peat having similar rates and coal having clearly the lowest average reaction rate. The similarities between the wood based materials are expected due to their similar composition. Peat is slightly less reactive than the woody materials, most likely due to larger shares of char and ash. Sewage sludge and coal have the lowest apparent reactivities, both containing the highest shares of ash. The tested waste fractions behave similarly to more commonly used biomass fuels, which differ from coal by reacting at significantly lower temperatures. The reaction rates are affected by the chemical composition of the material as well the diffusion characteristics near the sample and within pore structure 

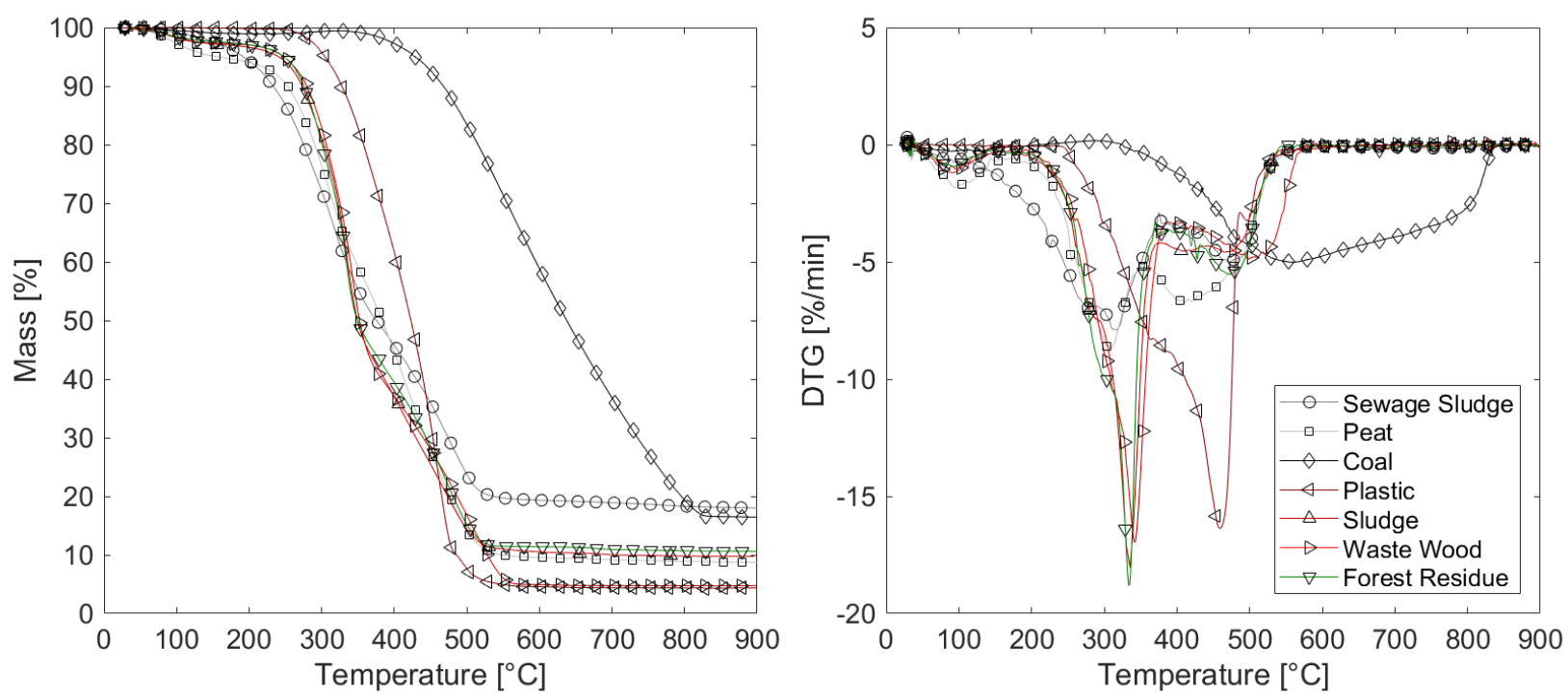

Figure 2. TGA measured curves of mass loss and derivate of mass loss (DTG).

\subsection{Reactivity characterization}

Figure 3 presents examples of FTIR measurements of major gaseous species from the combustion of coal and sewage sludge at $800{ }^{\circ} \mathrm{C}$ in ambient oxygen atmosphere. The main combustion products are $\mathrm{H}_{2} \mathrm{O}$ and $\mathrm{CO}_{2}$, followed by $\mathrm{CO}, \mathrm{SO}_{2}$, and $\mathrm{NO}$. The share of other species is relatively small compared to these previously mentioned products. As the samples were dried prior to the pelletization and experiments, and the evaporation of remaining moisture is fast at the reactor conditions, no notable drying is observed during the reactivity characterization. The data show a significant and fast release and subsequent combustion of volatile matter from the pellet, followed by slower char combustion. As most of the sample materials had a high share of volatile matter, their combustion reaction is dominated by combustion of the volatile compounds. With coal, the large char content is visible in the long duration of the reactions as well as the long tail in the measurement of the species. The drop in feed gas $\mathrm{O}_{2}$ concentration corresponds well with spikes in $\mathrm{H}_{2} \mathrm{O}, \mathrm{CO}_{2}$ and other product species. After volatiles release and combustion, the production of $\mathrm{H}_{2} \mathrm{O}$ is significantly reduced, while the production of $\mathrm{CO}_{2}$ reduces more slowly. This difference between the production of $\mathrm{H}_{2} \mathrm{O}$ and $\mathrm{CO}_{2}$ is one indication of end of volatile combustion and beginning of char combustion, as the char has a higher $\mathrm{C} / \mathrm{H}$-ratio. This behavior can be better observed in Figure 4 , where examples of scaled cumulative release profiles of all $\mathrm{C}, \mathrm{H}$, and $\mathrm{O}$ containing species (excluding the feed gas 
$\mathrm{O}_{2}$ ) are presented for coal and sewage sludge at $800{ }^{\circ} \mathrm{C}$ in ambient oxygen atmosphere. With coal, all $\mathrm{H}$

266 species are released within $50 \mathrm{~s}$ of the sample feeding, while all the $\mathrm{O}$ and $\mathrm{C}$ species are not released until 267130 to $170 \mathrm{~s}$ after feeding. With sewage sludge, all $\mathrm{H}$ containing species are released before $45 \mathrm{~s}$ and char combustion ends between 60 to $84 \mathrm{~s}$ after the sample feeding, illustrating the smaller amount of char and higher apparent reactivity. There is likely some overlap between combustion of volatiles and char due to differences in local combustion conditions, but it is considered that the contribution of char combustion is very small compared to volatile combustion and that the transition between volatiles-dominant combustion and char combustion is fast. This assumption is supported, for example, by the presence of two distinct gradients in the oxygen consumption and release profiles presented in Figures 3 and 4 . Some differences in the curves are visible most likely due to heterogeneity of the sample material. For this reason, data are averaged for the pellets which do not deviate significantly from the behavior of other pellets.

The reactivity characterization tests were performed in isothermal conditions with higher temperatures than required for most samples to react in the TGA, as well as having the sample pellet in direct gas flow through the grid, which increases the role of advection, while leaving the diffusion as the main mode of mass transfer within the sample pellets. These resulted in significantly faster reactions, especially with plastic, which had the largest apparent reactivity with the sample pellets melting and evaporating at very high rates.
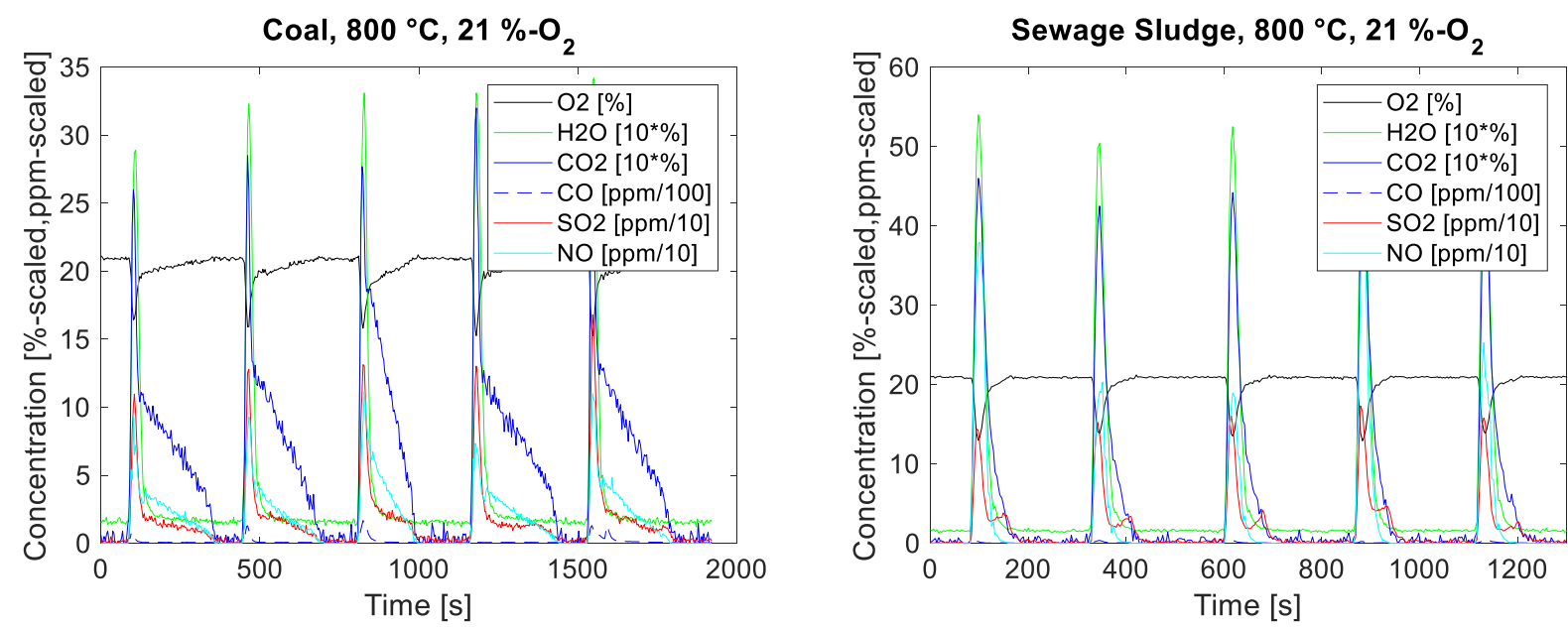

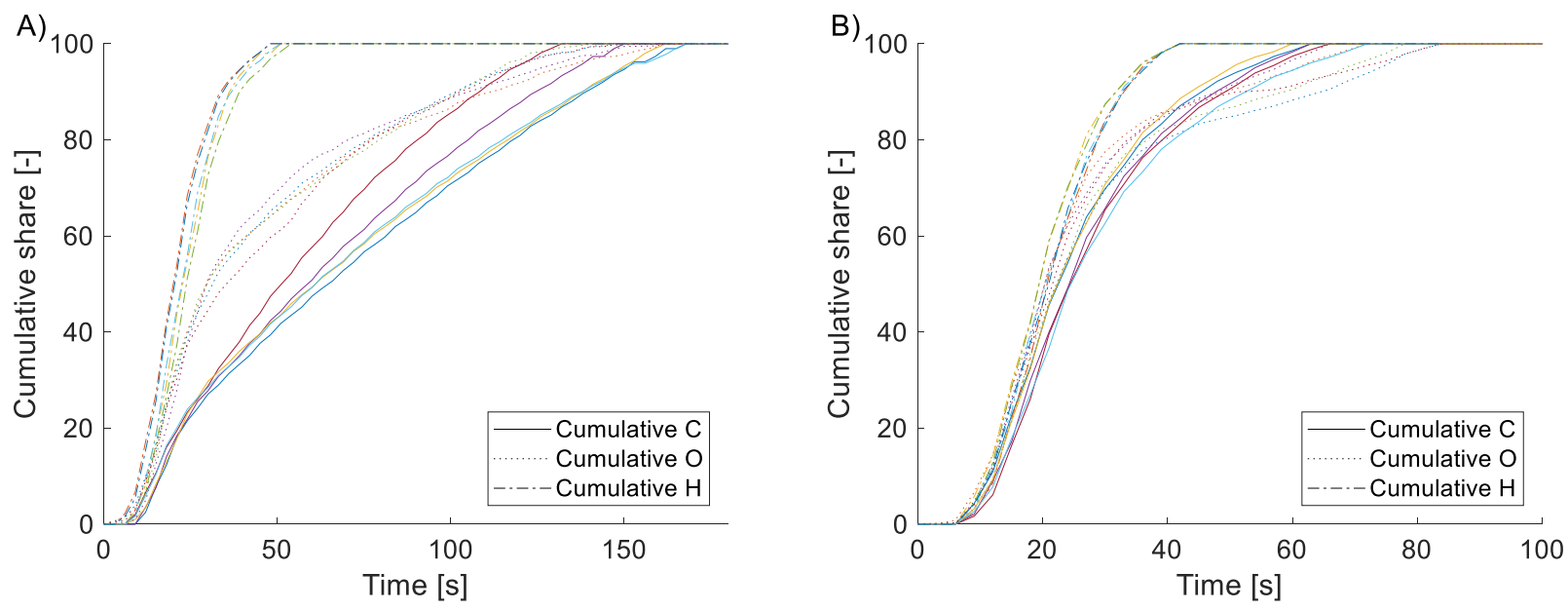

Figure 4. Example of cumulative shares of $\mathrm{C}, \mathrm{O}$ and $\mathrm{H}$ for $\mathrm{A}$ ) coal and B) sewage sludge at $800^{\circ} \mathrm{C}$ and $21 \%$-vol

oxygen. Different colors refer to different sample pellets while the line type refers to a specific element, solid line represents $\mathrm{C}$, dotted line $\mathrm{O}$ and dashed line $\mathrm{H}$.

\subsubsection{Reactivity at ambient oxygen concentrations}

Table 4 presents the reaction rate parameters for volatile and char combustion in ambient oxygen

concentrations. The apparent reactivity of plastic char appears to be reduced with increased temperature, but this is more likely a result of increased volatilization of already very low char content. For all other materials the char conversion rate increases with increasing temperature at a high coefficient of determination ( $R^{2}$-values). For the fast volatile conversion, the temporal sensitivity (sampling time) of the FTIR measurement setup was not sufficient to capture the dynamics of the volatile release and combustion with high confidence for all samples. The volatilization process might also crack or break some of the sample pellets, exposing more surface area and, as a result, increasing the reaction rate. However, good coefficients of determination for volatiles were obtained for liquid carton, waste wood, forest residue, sewage sludge, peat and coal.

Figure 5 presents a comparison of apparent reactivity of char and Figure 6 - of volatile reactivity at different temperatures with ambient oxygen concentrations scaled with the apparent reactivity of coal at $800{ }^{\circ} \mathrm{C}$. Of the chars, the peat and coal chars were the least reactive as expected based on the literature due to lower $\mathrm{O} / \mathrm{C}$ and $\mathrm{H} / \mathrm{C}$ ratios. Sewage sludge and industrial sludge also had low apparent reactivities which is likely due to their complex chemical composition. The wood-based materials had similar apparent reactivities 
with only slight deviation between the materials, most likely due to similar chemical composition.

306 Decomposition behavior of lignocellulosic materials generally follows a two-stages pattern: a complete 307 decomposition of hemicelluloses and cellulose and partial decomposition of lignin at the temperatures 308 below $370^{\circ} \mathrm{C}$; and the second combustion-degradation stage at higher temperatures that includes the decomposition of the remaining lignin and char oxidation [20,37]. This behavior is also visible in the TGA results of forest residue and waste wood. Notable exception among the studied cellulose-containing samples was paper, which was the second most reactive material after plastic. Similar result of high apparent reactivity of paper waste was reported by Skreiberg et al. [20]. There is a large share of ash in the paper, with additives such calcium carbonate and kaolin, which might act as a catalyst or at least make the paper char more porous, enabling faster diffusion of oxygen and a larger reaction surface area $[20,37,41]$.

The apparent reactivity of char in plastic appears to decrease with increases in temperature. The plastic had the smallest share of char and it is possible that the overlap between volatile and char combustion causes both the drop with temperature as well as the high apparent reactivity of char. Another possible reason for such behavior is heterogeneous nature of the sample: fractions of different types of plastics were mixed and this may result in certain unexpected reaction pathways. Several studies reported essential differences 320 in the reactivity and the combustion behavior for different types of plastics $[33,34]$.

321 When considering the volatiles, the release and combustion of volatile species was fast and typically quite complete when the oxygen concentration was $21 \%$, with only trace amounts of $\mathrm{CO}$ and $\mathrm{CH}_{4}$ of the carbon containing species measured during the experiments. The differences in the apparent reactivities of volatiles are smaller compared to char, though the data contains more uncertainty (lower and more varying $\mathrm{R}^{2}$-values between the materials). 
Table 4. Reactivity parameters at ambient oxygen concentration.

\begin{tabular}{|c|c|c|c|c|c|c|c|c|c|c|c|c|}
\hline \multirow[b]{2}{*}{$\mathrm{T}\left[{ }^{\circ} \mathrm{C}\right]$} & \multicolumn{3}{|c|}{ Volatiles k [1/s] } & \multicolumn{3}{|c|}{ Char k [1/s] } & \multicolumn{3}{|c|}{ Volatiles } & \multicolumn{3}{|c|}{ Char } \\
\hline & 700 & 800 & 900 & 700 & 800 & 900 & $\begin{array}{c}A \\
{[1 / s]}\end{array}$ & $\begin{array}{l}\mathrm{Ea} / \mathrm{R} \\
{[1 / \mathrm{K}]}\end{array}$ & $R^{2}$ & $\begin{array}{c}A \\
{[1 / s]}\end{array}$ & $\begin{array}{l}\mathrm{Ea} / \mathrm{R} \\
{[1 / \mathrm{K}]}\end{array}$ & $\mathrm{R}^{2}$ \\
\hline Paper & -2.395 & -3.785 & -4.028 & -0.029 & -0.036 & -0.040 & 4.04 & 364.14 & 0.876 & 1.55 & 230.19 & 0.973 \\
\hline Cartboard & -2.468 & -2.354 & -3.551 & -0.017 & -0.022 & -0.027 & 2.87 & 239.33 & 0.602 & 1.38 & 15.40 & 0.999 \\
\hline $\begin{array}{l}\text { Liquid } \\
\text { cartons }\end{array}$ & -1.807 & -2.040 & -2444 & -0.017 & -0.033 & -0.034 & 2.33 & 205.33 & 0.972 & 0.32 & 507.25 & 0.823 \\
\hline Plastic & -1.814 & -1.814 & -3.474 & -0.060 & -0.053 & -0.049 & 4.17 & 430.68 & 0.702 & 4.06 & -145.93 & 0.999 \\
\hline $\begin{array}{l}\text { Sewage } \\
\text { sludge }\end{array}$ & -1.935 & -1.976 & -2.050 & -0.017 & -0.019 & -0.022 & 0.99 & 39.38 & 0.958 & 2.61 & 169.18 & 0.989 \\
\hline $\begin{array}{l}\text { Waste } \\
\text { wood }\end{array}$ & -1.972 & -2.082 & 285 & -0.022 & 25 & 028 & 1.52 & 99.87 & 959 & 2.33 & 60 & .999 \\
\hline Bark & - & -2.44 & - & - & -0.024 & - & - & - & 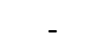 & - & - & - \\
\hline $\begin{array}{l}\text { Saw mill } \\
\text { residue }\end{array}$ & - & -2.657 & - & - & -0.027 & - & - & - & - & - & - & - \\
\hline $\begin{array}{l}\text { Forest } \\
\text { residue }\end{array}$ & -1.969 & -2.361 & -2.522 & -0.021 & -0.024 & -0.026 & 2.16 & 171.90 & 0.957 & 2.55 & 153.46 & 0.997 \\
\hline Peat & -1.969 & -2.316 & -2.531 & -0.014 & -0.015 & -0.015 & 2.17 & 173.48 & 0.987 & 3.82 & 49.17 & 0.962 \\
\hline Sludge & -2.434 & -1.982 & -2.709 & -0.015 & -0.017 & -0.024 & 1.95 & -62.18 & 0.082 & 1.76 & 286.01 & 0.881 \\
\hline Coal & -1.677 & -1.760 & -2.036 & -0.006 & -0.008 & -0.010 & 1.62 & 130.78 & 0.892 & 2.15 & 343.00 & 0.999 \\
\hline
\end{tabular}

328

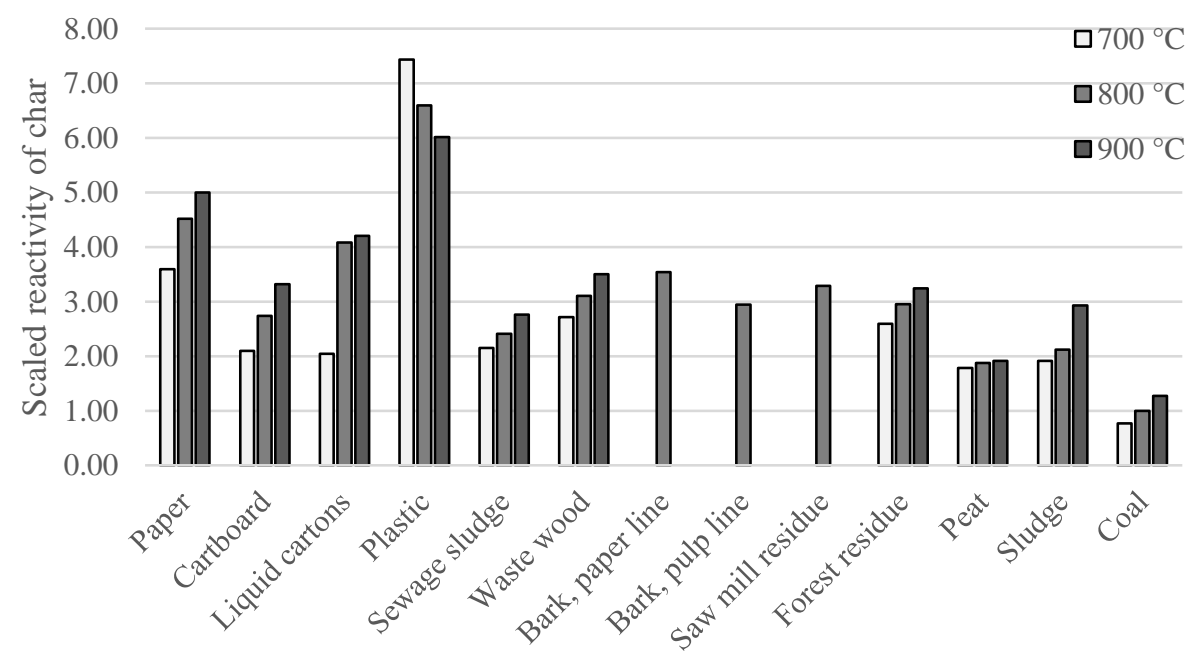

Figure 5 . Char reactivity at different temperatures scaled with coal char reactivity at $800^{\circ} \mathrm{C}$. 


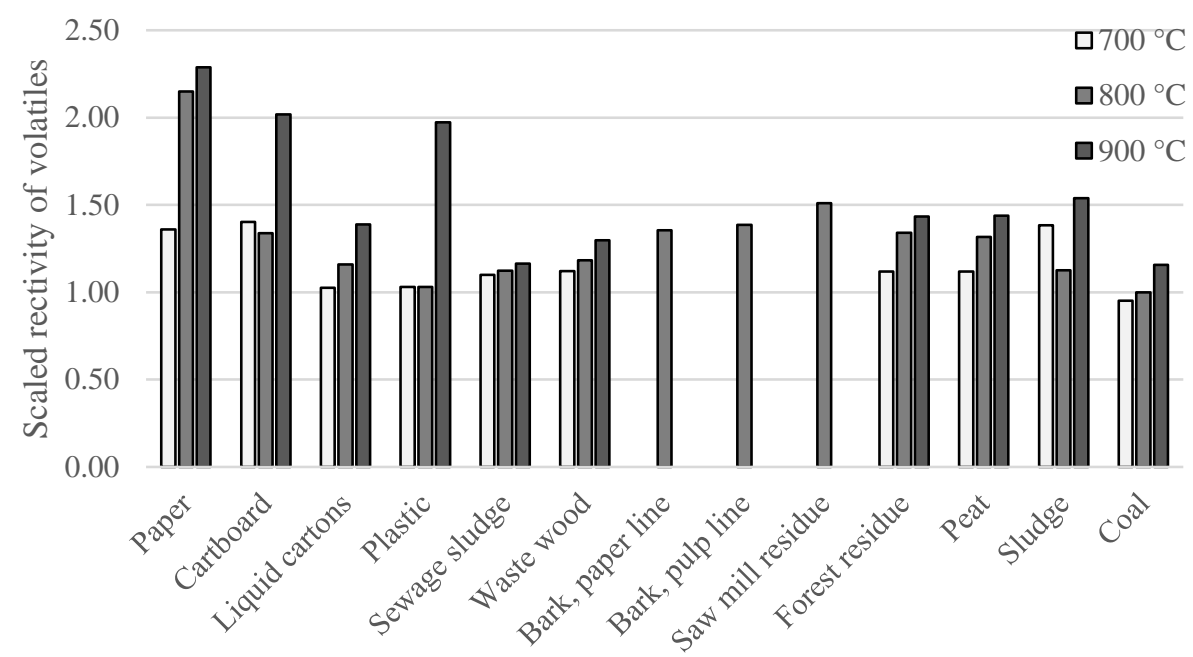

331

Figure 6. Reactivity of volatiles at different temperatures scaled with reactivity of coal volatiles at $800{ }^{\circ} \mathrm{C}$.

\subsubsection{Reactivity at lowered oxygen concentrations}

Table 5 presents reaction rate data for ambient and reduced oxygen concentrations at $800{ }^{\circ} \mathrm{C}$. These reduced oxygen concentrations better represent conditions inside incinerators, as the regions where the fuel is fed are oxygen-depleted due to fuel conversion reactions consuming the available oxygen. In general, the trend can be seen that reducing the oxygen content lowers the apparent reactivity of the volatiles and char, which, for example, is seen clearly with coal, though there are some exceptions in the data.

Devolatilization at $800{ }^{\circ} \mathrm{C}$ was very fast, but the reduced amount of oxygen limits the combustion of the volatiles, leading to incomplete combustion which is visible as larger amounts of gas species other than $\mathrm{CO}_{2}$ and $\mathrm{H}_{2} \mathrm{O}$ in the FTIR data. As the volatiles are not reacting to $\mathrm{CO}_{2}$ and $\mathrm{H}_{2} \mathrm{O}$, it is uncertain what the different species are as the utilized FTIR species library only includes 15 on the most common species of carbohydrates, therefore likely not detecting some of the released volatile species or even misinterpreting them as different species. Undetectable or misinterpreted carbon species are not acknowledeged or are misrepresented in the determination of the sample conversion. Additionally, concentrations of species that exceed the maximum range of the FTIR - equipment cause interference and unreliability in the measurement data. For plastics, the fast devolatilization and incomplete combustion caused the released amounts to exceed the measurement ranges of the FTIR - equipment for several components, for example 
$\mathrm{CH}_{4}$ and $\mathrm{CO}$, which ultimately rendered the measurement data unusable. Another issue was related to

351 difficulties in determining the end of volatile release and combustion and the beginning of char

352 combustion, as the char could gasify instead of burning. All the previously mentioned issues can cause

353 inaccuracy in the measurements in the reduced oxygen atmospheres, which might explain why there is no

354 clear trend with the change in oxygen concentration for some samples. Additionally, the FTIR sampling time

355 span was too long for reliable capture of the fast volatilization reactions, thus the volatilization results

356 contain a fairly high amount of uncertainty, while the effect was not as prominent on the char reactivity

357 determination. Reasonably good results for char combustion were obtained for waste wood, forest residue

358 and coal, which contain larger shares of char.

359 Figure 7 and Figure 8 present the apparent reactivities of the char and volatiles of the tested materials in

360 reduced and atmospheric oxygen concentrations at $800{ }^{\circ} \mathrm{C}$ scaled with the apparent reactivity of coal at 800

$361{ }^{\circ} \mathrm{C}$ in atmospheric oxygen concentration. This comparison shows that for coal the reduced oxygen

362 concentrations would reduce the char and volatiles reactivity. A similar reduction is visible for the volatile

363 reactivity of the sewage sludge, though the reduction is much smaller, while the char reactivity results are

364 inconsistent. With peat both results of char and volatile reactivity are inconsistent. For other samples, the

365 volatiles reactivity is increasing while the char reactivity is decreasing with decreasing oxygen concentration

366 as expected, for example, for waste wood, or the char reactivity remains at a constant reduced level, for

367 example, for sludge. The results on the combustion behavior of several materials with varying oxygen

368 concentration in presented by Zevenhoven et al. in [33] showed somewhat similar results for coal, however

369 a clear tendency was not always visible for plastics. 
Table 5. Reactivity parameters at ambient and reduced oxygen concentrations.

Volatiles k [1/s] Char k [1/s]

\begin{tabular}{ccccccc} 
Oxygen concentration [\%-vol] & 21 & 10 & 5 & 21 & 10 & 5 \\
\hline Sewage sludge & -1.976 & -1.870 & -1.835 & -0.019 & -0.017 & -0.020 \\
Waste wood & -2.082 & -2.268 & -2.579 & -0.025 & -0.014 & -0.010 \\
Forest residue & -2.361 & -2.472 & -2.692 & -0.024 & -0.013 & -0.011 \\
Peat & -2.316 & -2.082 & -2.613 & -0.015 & -0.008 & -0.009 \\
Sludge & -1.982 & -2.249 & -2.549 & -0.017 & -0.012 & -0.012 \\
Coal & -1.760 & -1.651 & -0.805 & -0.008 & -0.003 & -0.002 \\
\hline
\end{tabular}

372

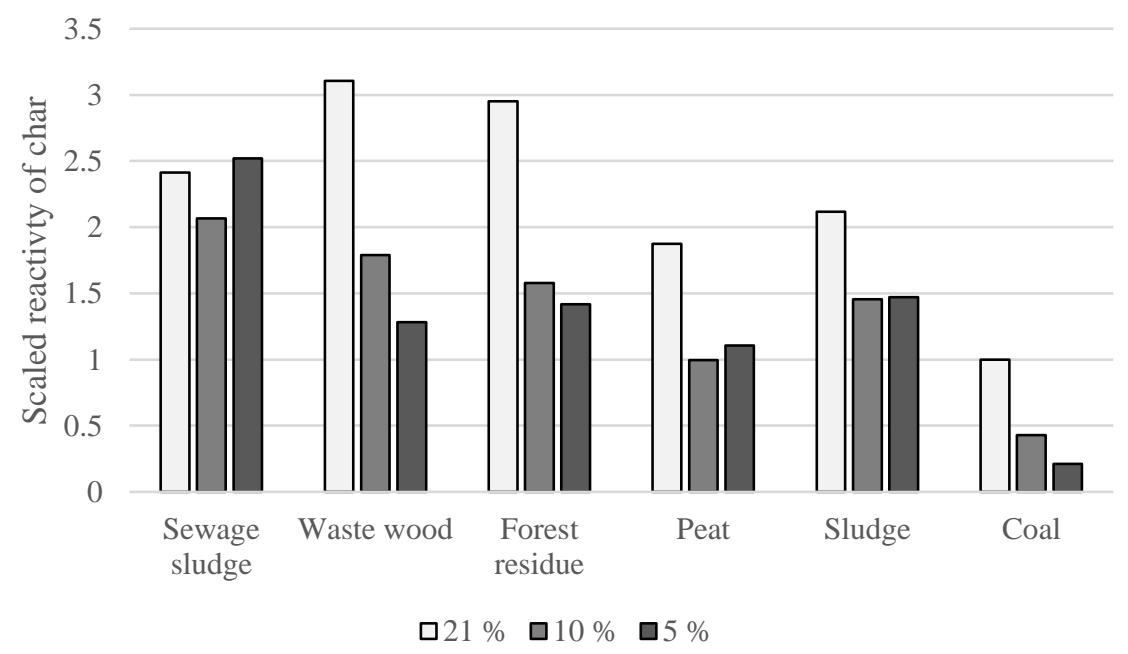

373

374 Figure 7. Char reactivity at different oxygen concentrations scaled with coal char reactivity at $800{ }^{\circ} \mathrm{C}$ and $21 \%$ oxygen concentration.

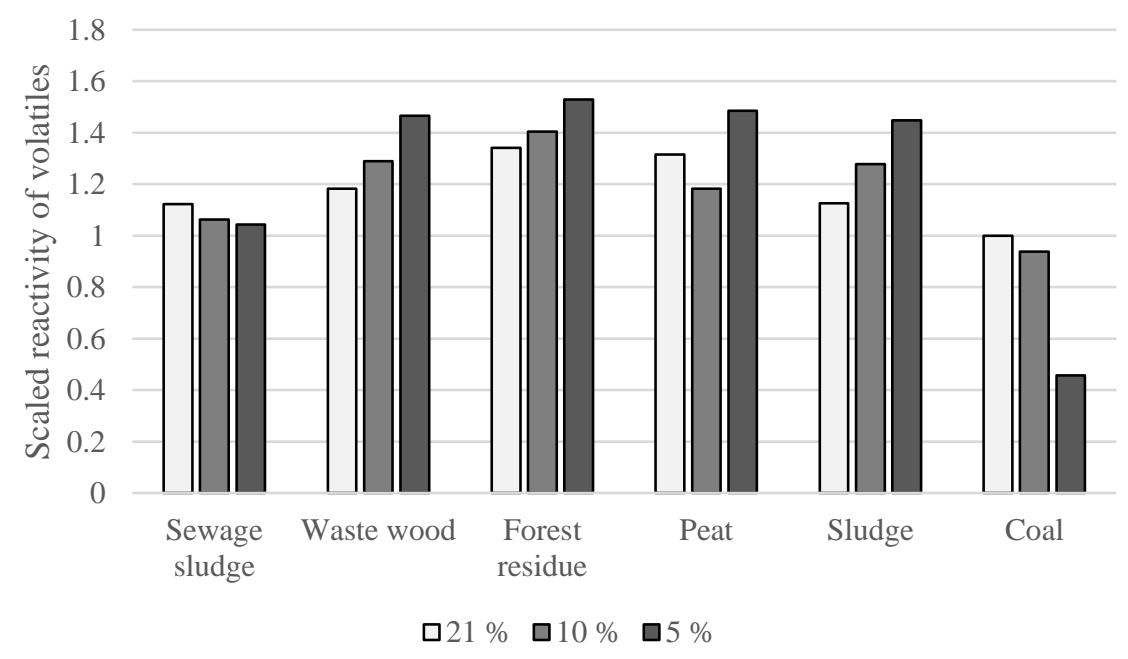

377 Figure 8. Reactivity of volatiles at different temperatures scaled with reactivity of coal volatiles at $800{ }^{\circ} \mathrm{C}$ and $21 \%$ oxygen concentration. 


\subsection{Comparison of TGA and benchscale}

Figure 9 presents the scaled apparent reactivity data to compare the TGA and benchscale characterization results. Benchscale results are scaled with the coal conversion (at $800{ }^{\circ} \mathrm{C}, 21 \%-\mathrm{O}_{2}$ ) and TGA results with the coal conversion in the TGA (Table 3). In both analyses, plastic had the highest reactivity, over 4 times higher than that of the coal with the benchscale device, while only 1.7 times higher compared to the TGA. Similarly with other sample materials, the apparent reactivities are lower and closer together with the TGA. The differences in the apparent reactivities between different samples in TGA are smaller, for example, the waste wood, forest residue and sludge have similar results. In benchscale, the differences in the apparent reactivities between the materials are notably larger, which could partially relate to the particle size used, as the TGA samples were finely ground powders compared to pellets in the benchscale device. Additionally, the smaller sample size in TGA may mean that the results are affected to a greater extent by the heterogeneity of the waste materials. The most likely explanations for these results are the differences in a) heating rates between the TGA and the benchscale device, with the slower heating rate in TGA causing the samples to react more slowly, and b) dominant transportation mode of oxidizer and products, with diffusion controlling the flow of oxygen and products in the sample cup in TGA, and advection/convection playing a larger role in benchscale where the grate allows the gas to flow directly to the surface of the sample. Taking into consideration these factors, the presented results are reasonable and expected. These results show that the characterization method has a significant effect on the outcome of the reactivity characterization, thus the selected characterization method should represent the application where the characterization information is utilized. 


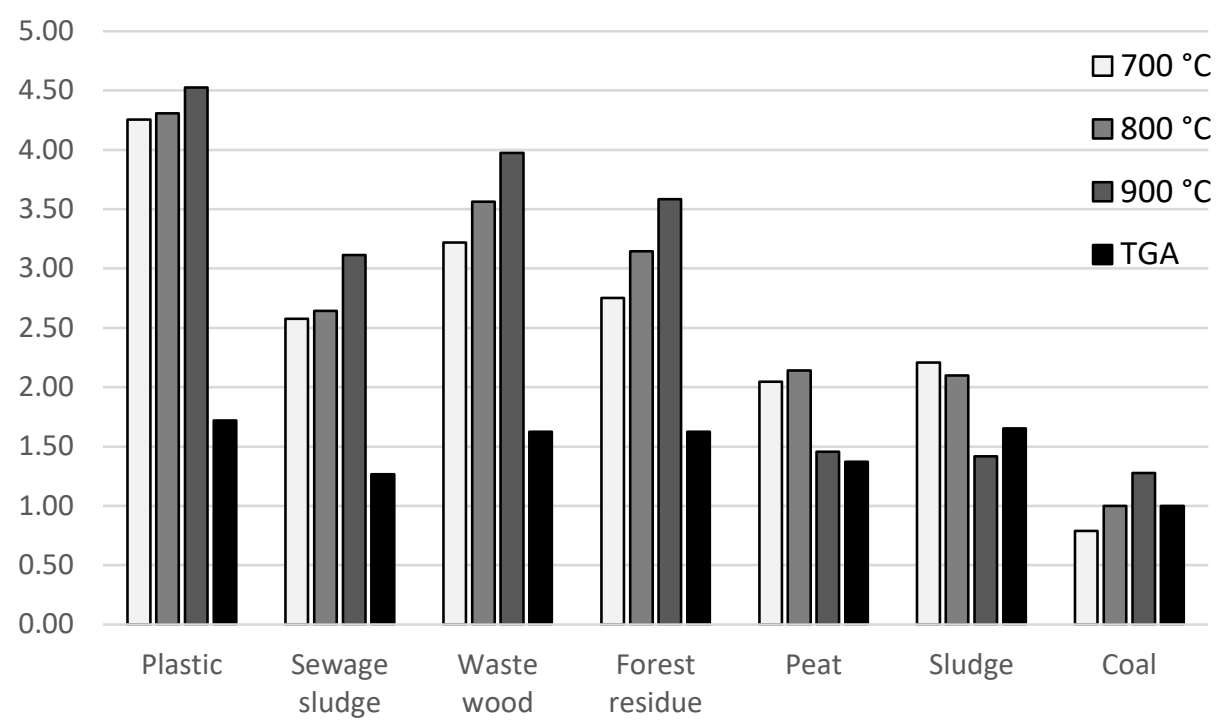

Figure 9. Comparison of total conversion rate relative to coal between the benchscale device and TGA.

\section{Conclusions}

402

403

404

405

406

407

408

409

410

The composition, heating value and apparent reactivity of a selection of solid waste materials was studied and compared to biomass and coal samples. The reactivity analysis was performed in a vertical tube reactor in which the pelletized sample was droped onto a porous grid and the conversion of the sample was monitored with FTIR. Thermogravimetric analysis was used for comparison of the reactivity results. Comparison of these two characterization methods illustrates that the characterization method has a significant effect on the apparent reaction rate results. As the selection of reactivity characterization method affects characterization results, the benchscale device offers conditions that better correspondence with reaction environments found in incinerator applications, such as grate firing incinerator for example.

- In the vertical tube reactor, the samples were exposed to a hot gas atmosphere and the reactions started earlier and occurred at a significantly faster rate than in the TGA with its slower and gradual heating.

- The used sample masses and particle sizes were different, with the benchscale allowing the utilization of larger sized particles which better represent the incinerator applications. TGA utilized 
a sample size of a few milligrams with sizes $<1 \mathrm{~mm}$, whereas $0.1 \mathrm{~g}$ pellets of $4 \mathrm{~mm}$ size were used in the benchscale. Le Manquais et al. [38] reported higher conversion rates for a drop tube compared to TGA for particles larger than $75 \mu \mathrm{m}$, which corresponds well with the findings of this work.

The presented characterization method would benefit from shorter sampling times $(\leq 1 \mathrm{~s})$ to better capture the rapid dynamics of devolatilization. With the current experimental setup, the sampling time of FTIR was too long to give high confidence on all the measured values, while still being able to qualitively capture the trends. In future work, equipment with faster sample acquisition and wider range should be utilized to increase the confidence of volatile combustion data. Currently, the method is well suited for slower char combustion characterization reactions, similarly to Fang et al. [27]. Further research is required to be able to accertain the reaction characteristics of different MSW fractions and their blends in non-TGA conditions.

\section{Acknowledgments}

439 This work was performed under the European Regional Development Fund project PAKUplus-HERGE 440 (A70015). 


\section{References}

[1] Chen G, Wang X, Li J, Yan B, Wang Y, Wu X, et al. Environmental, energy, and economic analysis of integrated treatment of municipal solid waste and sewage sludge: A case study in China. Sci Total Environ 2019;647:1433-43. doi:10.1016/J.SCITOTENV.2018.08.104.

[2] Li G, Hu Y. Comparisons of municipal solid waste incineration residues management in China and Europe. 2010 Int. Conf. Mech. Autom. Control Eng., 2010, p. 1972-5. doi:10.1109/MACE.2010.5536410.

[3] Nasrullah M. Material and energy balance of solid recovered fuel production. Aalto University, 2016.

[4] Horttanainen M, Teirasvuo N, Kapustina V, Hupponen M, Luoranen M. The composition, heating value and renewable share of the energy content of mixed municipal solid waste in Finland. Waste Manag 2013;33:2680-6. doi:10.1016/J.WASMAN.2013.08.017.

[5] Xiao G, Ni M, Chi Y, Jin B, Xiao R, Zhong Z, et al. Gasification characteristics of MSW and an ANN prediction model. Waste Manag 2009;29:240-4. doi:10.1016/J.WASMAN.2008.02.022.

[6] Liu Z, Liu Z, Li X. Status and prospect of the application of municipal solid waste incineration in China. Appl Therm Eng 2006;26:1193-7. doi:10.1016/J.APPLTHERMALENG.2005.07.036.

[7] Zhou H, Meng A, Long Y, Li Q, Zhang Y. An overview of characteristics of municipal solid waste fuel in China: Physical, chemical composition and heating value. Renew Sustain Energy Rev 2014;36:10722. doi:10.1016/J.RSER.2014.04.024.

[8] Murashko K, Nikku M, Sermyagina E, Vauterin JJ, Hyppänen T, Vakkilainen E, et al. Techno-economic analysis of a decentralized wastewater treatment plant operating in closed-loop. A Finnish case study. J Water Process Eng 2018;25:278-94. doi:10.1016/J.JWPE.2018.08.011.

[9] Roy MM, Dutta A, Corscadden K, Havard P, Dickie L. Review of biosolids management options and co-incineration of a biosolid-derived fuel. Waste Manag 2011;31:2228-35.

doi:10.1016/J.WASMAN.2011.06.008. 
465 [10] Chin S, Jurng J, Lee J-H, Hur J-H. Oxygen-enriched air for co-incineration of organic sludges with municipal solid waste: A pilot plant experiment. Waste Manag 2008;28:2684-9. doi:10.1016/J.WASMAN.2008.01.004.

[11] Nakakubo T, Yoshida N, Hattori Y. Analysis of greenhouse gas emission reductions by collaboratively 469 updating equipment in sewage treatment and municipal solid waste incineration plants. J Clean Prod 2017;168:803-13. doi:10.1016/J.JCLEPRO.2017.09.058.

[12] Lin $\mathrm{H}, \mathrm{Ma} X$. Simulation of co-incineration of sewage sludge with municipal solid waste in a grate furnace incinerator. Waste Manag 2012;32:561-7. doi:10.1016/J.WASMAN.2011.10.032.

[13] Li X, Zhang C, Li Y, Zhi Q. The Status of Municipal Solid Waste Incineration (MSWI) in China and its Clean Development. Energy Procedia 2016;104:498-503. doi:10.1016/J.EGYPRO.2016.12.084.

[14] Wissing F, Wirtz S, Scherer V. Simulating municipal solid waste incineration with a DEM/CFD method - Influences of waste properties, grate and furnace design. Fuel 2017;206:638-56. doi:10.1016/J.FUEL.2017.06.037.

[15] Simsek E, Brosch B, Wirtz S, Scherer V, Krüll F. Numerical simulation of grate firing systems using a doi:10.1016/J.POWTEC.2009.03.011.

[16] Liang Z, Ma X. Mathematical modeling of MSW combustion and SNCR in a full-scale municipal incinerator and effects of grate speed and oxygen-enriched atmospheres on operating conditions. Waste Manag 2010;30:2520-9. doi:10.1016/J.WASMAN.2010.05.006.

[17] Qin K, Thunman H. Diversity of chemical composition and combustion reactivity of various biomass fuels. Fuel 2015;147:161-9. doi:10.1016/J.FUEL.2015.01.047.

[18] Liu Y, Fu P, Zhang B, Yue F, Zhou H, Zheng C. Study on the surface active reactivity of coal char conversion in 02/CO2 and 02/N2 atmospheres. Fuel 2016;181:1244-56. doi:10.1016/J.FUEL.2016.01.077. 
[19] Munir S, Daood SS, Nimmo W, Cunliffe AM, Gibbs BM. Thermal analysis and devolatilization kinetics of cotton stalk, sugar cane bagasse and shea meal under nitrogen and air atmospheres. Bioresour Technol 2009;100:1413-8. doi:10.1016/J.BIORTECH.2008.07.065.

[20] Skreiberg A, Skreiberg $\varnothing$, Sandquist J, Sørum L. TGA and macro-TGA characterisation of biomass fuels and fuel mixtures. Fuel 2011;90:2182-97. doi:10.1016/J.FUEL.2011.02.012.

[21] Tolvanen H, Raiko R. An experimental study and numerical modeling of combusting two coal chars in a drop-tube reactor: A comparison between N2/O2, $\mathrm{CO} 2 / \mathrm{O} 2$, and N2/CO2/O2 atmospheres. Fuel 2014;124:190-201. doi:10.1016/j.fuel.2014.01.103.

[22] Cloke M, Lester E, Thompson AW. Combustion characteristics of coals using a drop-tube furnace. Fuel 2002;81:727-35. doi:10.1016/S0016-2361(01)00199-5.

[23] Sarroza AC, Bennet TD, Eastwick C, Liu H. Characterising pulverised fuel ignition in a visual drop tube furnace by use of a high-speed imaging technique. Fuel Process Technol 2017;157:1-11. doi:10.1016/j.fuproc.2016.11.002.

[24] Adeyemi I, Janajreh I, Arink T, Ghenai C. Gasification behavior of coal and woody biomass: Validation and parametrical study. Appl Energy 2017;185:1007-18. doi:10.1016/J.APENERGY.2016.05.119.

[25] Murphy JJ, Shaddix CR. Combustion kinetics of coal chars in oxygen-enriched environments. Combust Flame 2006;144:710-29. doi:10.1016/J.COMBUSTFLAME.2005.08.039.

[26] Kijo-Kleczkowska A, Środa K, Kosowska-Golachowska M, Musiał T, Wolski K. Experimental research of sewage sludge with coal and biomass co-combustion, in pellet form. Waste Manag 2016;53:16581. doi:10.1016/J.WASMAN.2016.04.021.

[27] Fang Y, Zou R, Luo G, Chen J, Li Z, Mao Z, et al. Kinetic Study on Coal Char Combustion in a Microfluidized Bed. Energy \& Fuels 2017;31:3243-52. doi:10.1021/acs.energyfuels.6b03137.

[28] Adamczyk WP, Szlęk A, Klimanek A, Białecki RA, Węcel G, Katelbach-Woźniak A, et al. Design of the experimental rig for retrieving kinetic data of char particles. Fuel Process Technol 2017;156:178-84. 
doi:10.1016/j.fuproc.2016.10.031.

514 [29] Tourunen A, Saastamoinen J, Hämäläinen J, Paakkinen K, Kettunen A, Hyppänen T. Dynamic measurements and analysis of fuel reactivity in a laboratory scale circulating fluidized bed combustor. Proc. 7th Conf. Circ. Fluid. Beds, 2002, p. 669-76.

[30] David C, Salvador S, Dirion JL, Quintard M. Determination of a reaction scheme for cardboard

[31] Lai Z, Ma X, Tang Y, Lin H, Chen Y. Thermogravimetric analyses of combustion of lignocellulosic

[32] Magdziarz A, Wilk M. Thermogravimetric study of biomass, sewage sludge and coal combustion.

[33] Zevenhoven R, Karlsson M, Hupa M, Frankenhaeuser M. Combustion and Gasification Properties of Plastics Particles. J Air Waste Manage Assoc 1997;47:861-70. doi:10.1080/10473289.1997.10464461.

[34] Wey MY, Chang CL. Kinetic study of polymer incineration. Polym Degrad Stab 1995;48:25-33. doi:10.1016/0141-3910(94)00125-R.

[35] Coimbra RN, Paniagua S, Escapa C, Calvo LF, Otero M. Combustion of primary and secondary pulp mill sludge and their respective blends with coal: A thermogravimetric assessment. Renew Energy 2015;83:1050-8. doi:10.1016/J.RENENE.2015.05.046.

[36] Yanfen L, Xiaoqian M. Thermogravimetric analysis of the co-combustion of coal and paper mill sludge. Appl Energy 2010;87:3526-32. doi:10.1016/J.APENERGY.2010.05.008.

[37] Gunasee SD, Carrier M, Gorgens JF, Mohee R. Pyrolysis and combustion of municipal solid wastes: Evaluation of synergistic effects using TGA-MS. J Anal Appl Pyrolysis 2016;121:50-61. 
doi:10.1016/J.JAAP.2016.07.001.

538 [38] Le Manquais K, Snape C, McRobbie I, Barker J, Pellegrini V. Comparison of the Combustion Reactivity 539 of TGA and Drop Tube Furnace Chars from a Bituminous Coal. Energy \& Fuels 2009;23:4269-77. doi:10.1021/ef900205d.

541 [39] Yi B, Zhang L, Huang F, Mao Z, Zheng C. Effect of $\mathrm{H} 2 \mathrm{O}$ on the combustion characteristics of pulverized coal in 02/CO2 atmosphere. Appl Energy 2014;132:349-57. doi:10.1016/J.APENERGY.2014.07.031.

544 [40] Li Q, Zhao C, Chen X, Wu W, Li Y. Comparison of pulverized coal combustion in air and in O2/CO2 545 mixtures by thermo-gravimetric analysis. J Anal Appl Pyrolysis 2009;85:521-8. doi:10.1016/J.JAAP.2008.10.018.

[41] Becidan M, Sørum L, Lindberg D. Impact of Municipal Solid Waste (MSW) Quality on the Behavior of 549 Alkali Metals and Trace Elements during Combustion: A Thermodynamic Equilibrium Analysis. Energy \& Fuels 2010;24:3446-55. doi:10.1021/ef901144u. 